\title{
Modelling the Impact of Tourism on Mental Health of Chinese Residents: An Empirical Study
}

\author{
Leilei Sun $\left(\mathbb{D},{ }^{1}\right.$ Guojun Wang $\mathbb{D}^{1},{ }^{1}$ and Lifei Gao ${ }^{2}{ }^{2}$ \\ ${ }^{1}$ School of Insurance and Economics, University of International Business and Economics, Beijing, China \\ ${ }^{2}$ School of Economics, Beijing Technology and Business University, Beijing, China \\ Correspondence should be addressed to Lifei Gao; lifeigao@btbu.edu.cn
}

Received 19 November 2021; Accepted 3 January 2022; Published 25 January 2022

Academic Editor: Daqing Gong

Copyright $($ C 2022 Leilei Sun et al. This is an open access article distributed under the Creative Commons Attribution License, which permits unrestricted use, distribution, and reproduction in any medium, provided the original work is properly cited.

\begin{abstract}
In the highly competitive social environment, people are facing psychological problems of anxiety, tension, and depression. This paper mainly examines the impact of tourism on negative emotions. This article uses the 2016 crosssectional data of the Chinese Family Panel Studies (CFPS) to observe the relationship between household tourism expenditures and the emotions of family members. We used the Probit model and instrumental variables and selected two types of negative emotions as indicators to measure the mental health to establish a model together with economic indicators such as family tourism expenditure and other economic activity expenditures. The empirical results show that families spending on tourism have low probability of negative emotions or mental problems $(P<0.01)$. There are positive effects between family tourism activities and members' mental health. It can be seen that tourism is an effective way to alleviate national mental health problems.
\end{abstract}

\section{Introduction}

2019 Gallup Global Emotions Report shows that worry and sadness across the world have reached record high (source: official website of Gallup, http://www.gallup.com). In 2018, Gallup asked adults in 142 countries if they had five different negative experiences on the day before the survey. More than one in three people said they experienced a lot of worry $(39 \%)$ or stress $(35 \%)$, and three in 10 experienced a lot of physical pain (31\%). At least one in five experienced sadness $(24 \%)$ or anger $(22 \%)$. While overall stress levels dropped two percentage points from the previous year, anger increased by two points-hitting a new high. Worry and sadness, which were already at record levels, increased by one point from the previous year. According to the Blue Book of Mental Health: China National Mental Health Development Report(2017-2018), Chinese people with rural household registration had "relatively poor" mental health than people with nonrural household registration, which has not changed much in four years. Mental health or emotional problems are becoming the main factors affecting people's quality of life.

As per WHO, mental health is a state of well-being in which an individual realizes his or her own abilities, can cope with the normal stresses of life, can work productively, and is able to make a contribution to his or her community (source: official website of WHO, http://www.who.int). Scholars have tackled this topic from different perspectives. Tang et al. believe that emotional adjusting self-efficacy is closely related to mental health [1]. They also quoted [1] stating that experiencing positive mood can enhance cognition, alleviate negative mood, and help people easily gain adaptive coping and active social interaction experience. The American psychologist Maslow believes one of the criteria of mental health is the proper emotional expression and control (the American psychologist Maslow put forward the 10 criteria judging the mental health: sufficient sense of safety; sufficient self-comprehension and proper evaluation of one's own ability; realistic life target; in 
touch with the real environment; maintaining personal integrity and harmony; ability to learn from the experience; sound interpersonal relations; proper emotional expression and control; exert limited individualism while not violating the team requirements; and ability to meet personal basic needs while not violating the social norms). Mood is the individual's adaptive coping mechanism to environment. Expressing and dissolving negative mood in specific time and situation and making active emotional regulation are considered indispensable process of social competence and mental health [1]. Liu and Cui, by comparing and analyzing a group with mental health issues before and after the tourism-related activities, concluded that travel activities help improve worry, depression, and other mental health problems [2]. de Nazelle et al. pointed out that governments can adopt the proactive tourism policies to guide the people to do proper amount of outdoor sports, so as to improve their mental health and achieve happiness [3]. At the same time, considering the health improvement after taking part in tourism-related activities, Fleck et al. believe that it might be attributed to the effect of entertainment and relaxation caused by the activities, and health-related tourism expenditures have positive influence on perceiving the health situation [4]. Researchers adopt different perspectives to study the mental health and draw analysis from the perspectives of group categorization $[5,6]$, active exercise effect [7-9], and medical expenditures [10], offering many feasible proposals and opinions. After COVID-19, researchers began to focus on the impact of tourism on mental health. The results show that outdoor tourism and entertainment can help people to improve their mood, relieve mental fatigue/stress, and generate mental health benefits [11-14]. Drawing on previous research, this article will, from the perspective of tourism expenditures made by the Chinese residents, empirically test the influence of tourism on the mental health of Chinese residents.

\section{Research Methodology}

2.1. Sample and Data Selection. The thesis adopts the 2016 cross-sectional data of the Chinese Family Panel Studies (CFPS) provided by the Institute of Social Science Survey, Peking University. The survey, which studies 58,179 families from 25 provinces and municipalities in China, includes all the major indicators such as family size and makeup, the family members' age, year of birth, marriage status, education, employment, physical and mental health, and so on as well as detailed data of family's financial situation such as incomes and consumption expenditures. This thesis selects data of only adults from CFPS since adults have decisive rights over expenditures. In total, the survey collects 35,632 adult samples. After eliminating the defective data, 24,015 samples remain. For the sake of study, the thesis uses the per capita tourism expenditure data of the entire family and the degree of negative mood of the residents, a non-economic indicator, as the measurement index of the mental health. It adopts STATA 14.0 for data analysis.
2.2. Variable Design. Family tourism spending is special expenditure on travel. The thesis uses the tourism expenditure data to show that residents have carried out tourismrelated activities, so as to establish the links between travel and personal negative mood or mental health state. We establish the regression equation by bearing upon the research results in the previous literature and referring to the influence factors of the mental health. The Probit model is used to make regression analysis:

$D_{i}=\mu_{i}+\beta_{1} T_{i}+\beta_{2} M_{i}+\beta_{3} I_{i}+\beta_{4} E_{i}+\beta_{5} R_{i}+\beta_{6} X_{i}+\varepsilon_{i}$,

$D_{i}= \begin{cases}0, & D_{i}<3, \\ 1, & D_{i} \geq 3,\end{cases}$

where $D_{i}$ stands for the virtual variable of the sadness and worry mood of the No. $i$ resident; $\mu_{i}$ represents the individual effect of the No. $i$ resident; $T_{i}$ stands for the tourism expenditure of the No. $i$ resident, which is replaced by the per capita tourism expenditure in the family (per capita tourism expenditures in the family= family tourism expenditure/number of family members) as the explanatory variable to observe its relations with $D_{i} ; M_{i}$ represents total medical expenses of the resident No. $i$, which studies relations between medical expenditures and negative mood of the residents; $I_{i}$ stands for the resident's total annual revenues from the work, which observes whether the revenues induce the negative mood; $E_{i}$ stands for the frequency of No. $I$ resident doing exercise, which observes to what extent the proper amount of sports impacts on the negative mood; $R_{i}$ represents the ratio of bringing up/supporting the kids/ parents of the No. $i$ resident (total proportion of bringing up/supporting the kids/parents $=$ (elderly population + juvenile population)/labor force population; in CFPS, select the living elderly people aged at or above 60 , and the juveniles aged below 18 before adding them to get the total family population that should be brought up/ supported; select the adults aged at or above 18 and below 60 as the labor force population in the family), which observes the family burdens and whether quality of life has impact on the negative mood; $X_{i}$ stands for the No. $I$ resident's variable of economic demography, including age, marriage status, education, employment, nature of the work and area, and so on, which observes the impact of these variables on the negative mood; and $\varepsilon_{i}$ is the stochastic term. Table 1 shows the descriptive statistical results of variables.

\section{Results}

3.1. Analytical Result. The thesis, at first, studies the impact of residents' travel on the probability of their sad mood. Results reveal that the evident level of tourism expenditures $(P<0.01)$ can reduce the residents' sad mood. To be specific, when proportion of tourism expenditures in the family life increases by $1 \%$, the sad mood goes down by $0.18 \%$, indicating that travel can effectively alleviate the negative mood and help improve the mental health. Table 2 shows estimation results of the model. 
Table 1: Descriptive statistics of variables.

\begin{tabular}{|c|c|c|c|c|c|c|}
\hline Variable & Variable definitions & Mean & Max & Min & SD & $\mathrm{N}$ \\
\hline Life depression & $\begin{array}{l}\text { The sample description "I do not think life can go on" represents the mood variable } \\
\text { of "sadness." Assignment: } 1=\text { the mood lasts } 3-7 \text { days; } 0=\text { the mood lasts } 0-2 \text { days }\end{array}$ & 0.030 & 1 & 0 & 0.172 & 24015 \\
\hline Lntravel & $\begin{array}{l}\text { The sample description "per capita tourism expenditure in the family" is the } \\
\text { explanatory variable that adopts the logarithmic form. }\end{array}$ & 1.309 & 11.23 & 0 & 2.633 & 24015 \\
\hline Lnmetotal & The sample description "total medical expenses" adopts the loga & 4.461 & 13.00 & 0 & 3.399 & 24015 \\
\hline Lnincome & The sample description "all revenues from the wor & 2.306 & 16.15 & 0 & 4.243 & 24015 \\
\hline $\begin{array}{l}\text { Exercise } \\
\text { frequency }\end{array}$ & $\begin{array}{l}\text { The sample description "frequency of doing exercise" takes week as the computing } \\
\text { cycle }\end{array}$ & 1.892 & 50 & 0 & 2.894 & 24015 \\
\hline $\begin{array}{l}\text { Dependency } \\
\text { ratio }\end{array}$ & (Elderly population + juvenile population)/labor force population & 0.287 & 6 & 0 & 0.549 & 24015 \\
\hline Employment & $\begin{array}{l}\text { The sample description "current state of work"; assignment } 1=\text { in employment; } \\
\qquad 0=\text { out of labor force market }\end{array}$ & 0.901 & 1 & 0 & 0.299 & 24015 \\
\hline Job nature & $\begin{array}{c}\text { The sample description "job nature"; assignment } 1=\text { agricultural job; } 0=\text { non- } \\
\text { agricultural job }\end{array}$ & 0.458 & 1 & 0 & 0.498 & 24015 \\
\hline & The sample & & 89 & 16 & & \\
\hline Single & The sample description "single"; the sample assignment is 1 . & & 1 & 0 & & 24015 \\
\hline Ever-married & The sample description "ever-married"; the sample assignment is 2 . & 0.875 & 1 & 0 & 0.330 & 24015 \\
\hline Coh & le description "cohabita & 0.004 & 1 & 0 & 0.062 & 24015 \\
\hline Divorce & The sample description "divorc & 0.018 & 1 & 0 & 0.132 & 24015 \\
\hline Education & $\begin{array}{l}\text { The sample description "highest education completed by the interviewee"; from the } \\
\text { illiterate to the doctorate, the assignment ranges from } 1 \text { to } 9 .\end{array}$ & 2.706 & 8 & 1 & 1.395 & 24015 \\
\hline
\end{tabular}

Source: 2016 Chinese Family Panel Studies (CFPS).

TABle 2: The impact of Probit model on estimation result of sad mood based on cross-sectional data.

\begin{tabular}{|c|c|c|c|}
\hline Variables & $\beta$ & $\beta$ & $\beta$ \\
\hline Lntravel $(T i)$ & $\begin{array}{c}-0.00481^{* * *} \\
(0.000570)\end{array}$ & $\begin{array}{c}-0.00218^{* * *} \\
(0.000612)\end{array}$ & $\begin{array}{c}-0.00179^{* * *} \\
(0.000619)\end{array}$ \\
\hline Lnmetotal $(M i)$ & & $\begin{array}{c}0.00309^{* * *} \\
(0.000385)\end{array}$ & $\begin{array}{l}0.00299^{* * *} \\
(0.000388)\end{array}$ \\
\hline Lnincome $(I i)$ & & $\begin{array}{c}0.000371 \\
(0.000368)\end{array}$ & $\begin{array}{c}0.000474 \\
(0.000368)\end{array}$ \\
\hline Exercise frequency $(E i)$ & & $\begin{array}{l}-0.000651 \\
(0.000404)\end{array}$ & $\begin{array}{l}-0.000629 \\
(0.000403)\end{array}$ \\
\hline Dependency ratio $(R i)$ & & $\begin{array}{l}-0.00144 \\
(0.00265)\end{array}$ & $\begin{array}{l}-0.00186 \\
(0.00261)\end{array}$ \\
\hline Employment $\left(X_{i}\right)$ & & $\begin{array}{c}-0.0161^{* * *} \\
(0.00336)\end{array}$ & $\begin{array}{c}-0.0172^{* * *} \\
(0.00334)\end{array}$ \\
\hline Job nature $\left(X_{i}\right)$ & & $\begin{array}{c}0.0106^{* * *} \\
(0.00287)\end{array}$ & $\begin{array}{c}0.00684^{* *} \\
(0.00294)\end{array}$ \\
\hline Age $\left(X_{i}\right)$ & & $\begin{array}{c}0.00101^{*} \\
(0.000588)\end{array}$ & $\begin{array}{c}0.00106^{*} \\
(0.000585)\end{array}$ \\
\hline Age 2 & & $\begin{array}{l}-0.000832 \\
(0.000587)\end{array}$ & $\begin{array}{l}-0.000738 \\
(0.000582)\end{array}$ \\
\hline Ever-married $\left(X_{i}\right)$ & & $\begin{array}{c}-0.0117^{* *} \\
(0.00554)\end{array}$ & $\begin{array}{c}-0.0113^{* *} \\
(0.00549)\end{array}$ \\
\hline Cohabitation $\left(X_{i}\right)$ & & $\begin{array}{l}0.00361 \\
(0.0162)\end{array}$ & $\begin{array}{l}0.00329 \\
(0.0159)\end{array}$ \\
\hline Divorce $\left(X_{i}\right)$ & & $\begin{array}{c}0.0178^{* *} \\
(0.00880)\end{array}$ & $\begin{array}{l}0.0189^{* *} \\
(0.00873)\end{array}$ \\
\hline Education $\left(X_{i}\right)$ & & $\begin{array}{c}-0.0120^{* * *} \\
(0.00127)\end{array}$ & $\begin{array}{c}-0.0109^{* * *} \\
(0.00126)\end{array}$ \\
\hline Provincial effect $\left(X_{i}\right)$ & No & No & Yes \\
\hline Observations & 24015 & 24015 & 24015 \\
\hline
\end{tabular}

Note. Values included in the bracket represent the robust standard error. *, ${ }^{* *}$, and ${ }^{* * *}$ represent, respectively, the evident results in the levels of $10 \%$, $5 \%$, and $1 \%$.

\subsection{Robustness Test}

3.2.1. Considering the Endogeneity. In light of possible selfselection problem in family tourism expenses, which might result in deviated regression results, the study utilizes the logarithm of "average tourism expenses in other community-level families" (per capita tourism expenditure in other families at the community level $=$ total tourism expenditures in other families in the community/total number of families in the community) as the instrumental variable to make regression analysis. The Wald exogeneity test of IVProbit model reveals that refusal of null hypothesis (the value is 4.29 and $p$ value is 0.0383 ) shows that explanatory variable has its endogeneity. As a result, instrumental variable should be used for the sake of modification. Table 3 shows the results of the two-phase least square method. The phase-1 regression result reveals that the coefficient of the instrumental variable is 0.02206 . The evident result in $1 \%$ statistical level $(t$ value is 24.00 and $p$ is $\leq 0.001$ ) demonstrates that it is significantly correlated to the explanatory variable, proving that the instrumental variable meets three basic requirements, namely, exogeneity, strong correlation with explanatory variable, and satisfying exclusivity. Table 3 displays the phase-2 regression result. In $1 \%$ statistical level, tourism still evidently lowers the probability of occurrence of negative mood, proving that tourism activities undertaken without exceeding the limits are beneficial to psychological health.

3.2.2. Studying Other Mental Health Factors of the Same Nature as the Interrelations between the Explanatory Variable and Tourism Expenditures. To test the robustness of the 
TABLE 3: Result of using instrumental variable to test the endogeneity of explanatory variable.

\begin{tabular}{|c|c|c|c|}
\hline Variables & IVProbit $\beta$ life_depress travel_dum & IVProbit $\beta$ life_depress travel_dum & IVProbit $\beta$ life_depress travel_dum \\
\hline Travel_dum & $\begin{array}{c}-0.898^{* * *} \\
(0.183)\end{array}$ & $\begin{array}{c}-0.788^{* * *} \\
(0.257)\end{array}$ & $\begin{array}{c}-0.738^{* *} \\
(0.295)\end{array}$ \\
\hline Lnmetotal & & $\begin{array}{c}0.0499^{* * *} \\
(0.00573)\end{array}$ & $\begin{array}{c}0.0493^{* * *} \\
(0.00589)\end{array}$ \\
\hline Lnincome & & $\begin{array}{c}0.00467 \\
(0.00559)\end{array}$ & $\begin{array}{c}0.00643 \\
(0.00572)\end{array}$ \\
\hline Exercise frequency & & $\begin{array}{c}-0.00504 \\
(0.00657)\end{array}$ & $\begin{array}{l}-0.00521 \\
(0.00680)\end{array}$ \\
\hline Dependency ratio & & $\begin{array}{l}-0.0174 \\
(0.0395)\end{array}$ & $\begin{array}{l}-0.0262 \\
(0.0405)\end{array}$ \\
\hline Employment & & $\begin{array}{c}-0.228^{* * *} \\
(0.0526)\end{array}$ & $\begin{array}{c}-0.253^{* * *} \\
(0.0537)\end{array}$ \\
\hline Job nature & & $\begin{array}{c}0.0846 \\
(0.0568)\end{array}$ & $\begin{array}{c}0.0461 \\
(0.0570)\end{array}$ \\
\hline Age & & $\begin{array}{c}0.0163^{*} \\
(0.00845)\end{array}$ & $\begin{array}{l}0.0170^{* *} \\
(0.00861)\end{array}$ \\
\hline Age 2 & & $\begin{array}{l}-0.0130 \\
(0.00839)\end{array}$ & $\begin{array}{l}-0.0117 \\
(0.00855)\end{array}$ \\
\hline Ever-married & & $\begin{array}{l}-0.127 \\
(0.0830)\end{array}$ & $\begin{array}{c}-0.124 \\
(0.0859)\end{array}$ \\
\hline Cohabitation & & $\begin{array}{c}0.109 \\
(0.263)\end{array}$ & $\begin{array}{c}0.107 \\
(0.273)\end{array}$ \\
\hline Divorce & & $\begin{array}{r}0.282^{* *} \\
(0.132)\end{array}$ & $\begin{array}{r}0.303^{* *} \\
(0.135)\end{array}$ \\
\hline Education & & $\begin{array}{c}-0.138^{* * *} \\
(0.0270)\end{array}$ & $\begin{array}{c}-0.130^{* * *} \\
(0.0286)\end{array}$ \\
\hline Constant & $\begin{array}{c}-1.711^{* * *} \\
(0.0396)\end{array}$ & $\begin{array}{c}-1.872^{* * *} \\
(0.199)\end{array}$ & $\begin{array}{c}-0.738^{* *} \\
(0.295)\end{array}$ \\
\hline Provincial effect & No & No & Yes \\
\hline Observations & 24015 & 24015 & 24015 \\
\hline
\end{tabular}

Note. Values included in the bracket refer to the robust standard error. ${ }^{*},{ }^{* *}$, and ${ }^{* * *}$ represent, respectively, the evident results in the levels of $10 \%, 5 \%$, and $1 \%$.

regression analysis, select the "inferiority" mental health problem in the "negative" mood (the sample description is "I find it difficult to do anything," whose assignment is the same as the "sadness" mood) and per capita tourism expenditures of the family to make another regression. Table 4 shows the result of regression. For residents with the mental health issues, represented by the negative mood of the same nature, their mental health problem improved at the $1 \%$ evident level after taking part in travel-related activities. This proves that proper tourism plays certain role in reducing probability of other negative moods of the same nature and can alleviate the mental health problem.

\section{Discussion}

From the regression results, there is a certain causal relationship between tourism and mental health. Appropriate tourism activities can help adjust impact of negative mood on the people. In the real scenarios of pleasure and relaxation, the positive and active instant emotional experience can, to some extent, adjust the time perception and avoid the continued lengthening of negative mood time perception while adjusting the personal emotional state. This also proves the conclusions reached by Huang and Zou, e.g., the subhealth group (subhealth is the state of low-quality health caused by natural endowment, society, psychology and nature, etc., working together on human body [18]) prefers traveling with kinsfolk in the form of family for the sake of pleasure and tranquility [15]. The outdoor tourism and recreation can contribute powerfully to the well-being of women and families. At least some outdoor tourism and experiences can generate mental health benefits that may include preventive components [14]. Therefore, improving travelers' mental health and well-being is becoming the primary task of the tourism industry.

From other variables of the model, in addition to the family's tourism expenditure, the family's total medical expenditure and the employment status of members also have an impact on mental health. The evident homodromous influence of total medical expenditures and negative mood such as sadness at the $1 \%$ statistical level proves that residents with heavy medical expenditures have larger probability of mental health problems. Pan et al. find that the government-subsidized medical insurance can positively affect the insured's subjective evaluation of self-health. From another point of view, it shows that the pressure of paying medical expenditures will affect residents' health [10]. The employment state has different degrees of evident influence on the two kinds of negative mood. The employed people have low negative mood while the unemployed have high 
TABle 4: Result of evaluation of other negative moods in Probit model.

\begin{tabular}{|c|c|c|c|}
\hline Variables & $\beta$ & $\beta$ & $\beta$ \\
\hline Lntravel & $\begin{array}{r}-0.0118^{* * *} \\
(0.000929)\end{array}$ & $\begin{array}{c}-0.00496^{* * *} \\
(0.00101)\end{array}$ & $\begin{array}{c}-0.00434^{* * *} \\
(0.00103)\end{array}$ \\
\hline Lnmetotal & & $\begin{array}{c}0.0106^{* * *} \\
(0.000688)\end{array}$ & $\begin{array}{l}0.0104^{* * *} \\
(0.000698)\end{array}$ \\
\hline Lnincome & & $\begin{array}{c}0.000762 \\
(0.000643)\end{array}$ & $\begin{array}{c}0.000808 \\
(0.000642)\end{array}$ \\
\hline Exercise frequency & & $\begin{array}{l}-0.000176 \\
(0.000763)\end{array}$ & $\begin{array}{l}-0.000183 \\
(0.000760)\end{array}$ \\
\hline Dependency ratio & & $\begin{array}{c}0.00646 \\
(0.00453)\end{array}$ & $\begin{array}{c}0.00604 \\
(0.00451)\end{array}$ \\
\hline Employment & & $\begin{array}{c}-0.0499^{* * *} \\
(0.00655)\end{array}$ & $\begin{array}{c}-0.0511^{* * *} \\
(0.00654)\end{array}$ \\
\hline Job nature & & $\begin{array}{c}0.0259^{* * * *} \\
(0.00536)\end{array}$ & $\begin{array}{c}0.0200^{* * *} \\
(0.00553)\end{array}$ \\
\hline Age & & $\begin{array}{c}0.00293^{* * *} \\
(0.00106)\end{array}$ & $\begin{array}{c}0.00299^{* * *} \\
(0.00107)\end{array}$ \\
\hline Age 2 & & $\begin{array}{l}-0.00136 \\
(0.00108)\end{array}$ & $\begin{array}{l}-0.00118 \\
(0.00108)\end{array}$ \\
\hline Ever-married & & $\begin{array}{l}-0.0135 \\
(0.0100)\end{array}$ & $\begin{array}{l}-0.0143 \\
(0.0101)\end{array}$ \\
\hline Cohabitation & & $\begin{array}{c}0.0267 \\
(0.0323)\end{array}$ & $\begin{array}{c}0.0179 \\
(0.0322)\end{array}$ \\
\hline Divorce & & $\begin{array}{l}0.0316^{*} \\
(0.0181)\end{array}$ & $\begin{array}{l}0.0326^{*} \\
(0.0180)\end{array}$ \\
\hline Education & & $\begin{array}{c}-0.0233^{* * *} \\
(0.00202)\end{array}$ & $\begin{array}{c}-0.0210^{* * * *} \\
(0.00204)\end{array}$ \\
\hline Provincial effect & No & No & Yes \\
\hline Observations & 24015 & 24015 & 24015 \\
\hline
\end{tabular}

Note. Values included in the bracket refer to the robust standard error. ${ }^{*},{ }^{* *}$, and ${ }^{* * *}$ represent, respectively, the evident results in the levels of $10 \%, 5 \%$, and $1 \%$.

negative mood mainly because the people out of the labor force market (excluding the retired people) face the pressure of reemployment. The instant emotional stimulation pressure would lengthen the perception of the time interval, making people feel "a much too long day" [16].

\section{Conclusion}

Based on the fact that Chinese residents have negative emotions, this paper makes an empirical analysis and preliminary exploration on the driving factors and consequences of Chinese residents' mental health from the perspective of psychological and emotional motivation, using the analysis framework that household economic behaviors drive residents' emotional changes. Studies have found that families with tourism expenses have a low probability of mental illness and a harmonious family life. At present, there are a few research studies on the relationship between tourism and mental health. After COVID-19, literatures on the relationship between travel activities and mental health have gradually increased. Rezaei et al. observed that agricultural tourism can help improve mood and achieve happiness in South Korea. As an emerging green activity, agritourism contributes to improving mental health [11]. In the process of studying the causal relationship between outdoor natural tourism and human mental health, Buckley used a questionnaire to find that there are 82 percent of people who said nature tourism made them happy [17].

This research finds that there is a comprehensive effect and positive effect between tourism and mental health, which provides favorable theoretical support for the tourism industry to reform and innovate products. In tourism activities, mental health cognition triggers individual behavioral intention for leisure products, such as consumption of luxury restaurants in tourism. It proves that customers' mental health and happiness are based on product performance [12]. As urban pollution leads to environmental pollution, "clean air and clean water" or "forest oxygen bar" becomes the conceptual product of tourism, where time spent in a pristine natural environment relieves the pressure from stressful urban life [13].

This paper studies the relationship between tourism and national mental health from the perspective of Chinese family tourism expenditure. This research method is relatively novel, but it also has some limitations. Taking family members as the research object, it is faced with diversified tourism demand including the purpose of adjusting emotional state. Although the research conclusion shows that tourism can promote mental health, in practical application, the development direction of tourism products is not clear enough. The fast pace of China's economic development makes the people in a tense emotional state for a long time, and the problems of emotional management and mental health are becoming more and more prominent. As an industry, tourism can improve people's well-being and mental health, and it will achieve great development. Commercial tourism suppliers will provide more tourism products based on improving mental health effects. In the future, the research on national mental health problems will be more closely combined with tourism demand and tourism products, and guide tourism investors to highlight the spiritual comfort effect of the elderly group [8] when investing in leisure and health industry. When investing in parent-child tourism industry, they can highlight the complementarity of family affection and growth education, so as to make tourism truly become an effective way to improve the mental health of Chinese people [18-24].

\section{Data Availability}

The cross-sectional data used to support the findings of this study were supplied by the Chinese Family Panel Studies (CFPS) provided by the Institute of Social Science Survey, Peking University, under license and so cannot be made freely available. Requests for access to these data should be made to http://www.isss.pku.edu.cn/cfps/en/index.htm?CS RFT=TOQG-D9F3-6M64-CH67-U244-ZP4R-SZ8L-OMJ2.

\section{Conflicts of Interest}

The authors declare that there are no conflicts of interest. 


\section{References}

[1] D. Tang, Y. Dong, G. Yu, and S. Wen, "The regulatory emotional self-efficacy:A new research topic," Advances in Psychological Science, vol. 18, no. 4, 2010.

[2] S. Liu and X. Cui, "Discussion on travel benefit to mental health-based on empirical analysis of survey data," Tourism Forum, vol. 3, 2013.

[3] A. de Nazelle, J. N. Mark, J. M. Antó et al., "Improving health through policies that promote active travel: a review of evidence to support integrated health impact assessment," Environment International, vol. 37, no. 4, pp. 766-777, 2011.

[4] S. Fleck, H. Jäger, and H. Zeeb, "Travel and health status: a survey follow-up study," The European Journal of Public Health, vol. 16, no. 1, pp. 96-100, 2006.

[5] Z. Chen, X. Zhang, X. Chen et al., "Relationship between depression and self-rated health among floating populations," Chinese Journal of Health Education, vol. 22, no. 10, 2006.

[6] L. Shu and G. Chen, "The employment effects of happiness-an empirical study on happiness, employment and recessive reemployment," Economic Research Journal, vol. 50, no. 3, 2015.

[7] Y. Sun, Z. Wang, J. Yao, J. Chengsu, Q. Dai, and Y. Jin, "Physical exercise and mental health:cognition, anxiety, depression and self-concept," Progress in Physiological Sciences, vol. 45, no. 5, pp. 337-342, 2014.

[8] Y. Song, H. Zhang, and L. Long, "Remained elderly, square dance and health benefits:an analysis of promotion of recreational activities for remained elderly's health," Population and Development, no. 5, pp. 97-104, 2015.

[9] J. Guan, G. Wang, and C. Geng, "The impact of different levels of physical activity on health among middle-aged and elderly Chinese adults," Iranian journal of public health, vol. 48, no. 11, pp. 1971-1978, 2019.

[10] J. Pan, X. Lei, and G. Liu, "Does health insurance lead to better health? - empirical analysis based on the basic medical insurance of the urban residents in China," Economic Research Journal, no. 4, pp. 130-156, 2013.

[11] M. Rezaei, D. Kim, A. Alizadeh, and L. Rokni, "Evaluating the mental-health positive impacts of agritourism; A case study from South Korea," Sustainability, vol. 13, no. 16, https:// www.mdpi.com/journal/sustainability, Article ID 8712, 2021.

[12] H. Han, Bo Meng, B.-L. Chua, and H. B. Ryu, "Hedonic and utilitarian performances as determinants of mental health and pro-social behaviors among volunteer tourists," International Journal of Environmental Research and Public Health, vol. 17, no. 18, Article ID 6594, 2020.

[13] R. Buckley, L. Zhong, and S. Martin, "Mental health key to tourism infrastructure in China's new megapark," Tourism Management, vol. 82, Article ID 104169, 2021.

[14] R. Buckley and D. Westaway, "Mental health rescue effects of women's outdoor tourism: a role in COVID-19 recovery," Annals of Tourism Research, vol. 85, Article ID 103041, 2020.

[15] H. Huang and J. Zou, "Urban travel behavior and preferences research under the perspective of sub-health," Yunnan Geographic Environment Research, vol. 1, 2013.

[16] Q. Cui, Ke Zhao, and X. Fu, "The mode of action and cognitive neural mechanisms in emotional modulation of interval timing," Progress in Biochemistry and Biophysics, vol. 45, no. 4, 2018.

[17] R. Buckley, "Nature tourism and mental health: parks, happiness, and causation," Journal of Sustainable Tourism, vol. 28, no. 9,2020 .
[18] J. D. Burkholder, R. Joines, M. Cunningham-Hill, and B. Xu, "Health and well-being factors associated with international business travel," Journal of Travel Medicine, vol. 17, no. 5, pp. 329-333, 2010.

[19] S. Shan, B. Xue, X. Dong, X. Zhou, and X. Zhao, "Intervention of sub-health state by applying TCM theory and psychological methods," Chinese Journal of Convalescent Medicine, vol. 6, 2011.

[20] A. Gafni and G. W. Torrance, "Risk attitude and time preference in health," Management Science, vol. 30, no. 4, 1984.

[21] X. Y. Lehto, Y. C. Lin, Y. Chen, and S. Choi, "Family vacation activities and family cohesion," Journal of Travel \& Tourism Marketing, vol. 29, no. 8, pp. 835-850, 2012.

[22] S. M. Srinivasan, P. Shah, and S. S. Surendra, "An approach to enhance business intelligence and operations by sentimental analysis," Journal of System and Management Sciences, vol. 11, no. 3, pp. 27-40, 2021.

[23] Y. Zhang, "About criteria of mental health," Consumer Guide, vol. 1, 2015.

[24] H. Han, S. Lee, A. Ariza-Montes et al., "Muslim travelers' inconvenient tourism experience and self-rated mental health at a non-islamic country: exploring gender and age differences," International Journal of Environmental Research and Public Health, vol. 18, no. 2, Article ID 758, 2021. 